\title{
The single most important intervention to tackle obesity...
}

\author{
Harry Rutter
}

Published online: 3 July 2012

(C) Swiss School of Public Health 2012

Keywords Obesity - Systems - Complexity · Paradigm shift

I was asked recently to name the single most important intervention to reduce childhood obesity. My weary reply was that the single most important intervention is to understand that there is no single most important intervention. This was greeted with predictable dismay, and groans of derision from my colleagues, who chided me for imperious ivory-towered idealism. But I stand by my response.

Obesity is the outcome of a complex web of social, cultural, environmental, biological and psychological influences. As has recently been described in this journal (Raine 2012) people's diets and physical activity exist within an ecological system of human behaviour that requires upstream actions to shift it. The system map produced for the UK Government's Foresight report clearly shows how this complex system acts at all levels of society, with numerous linkages and interactions (Butland et al. 2007; Finegood et al. 2010). But what do we need to do fully to understand a complex system such as this, and more importantly how do we decide how best to respond to it?

The scientific underpinnings of public health have made huge advances in recent years, building to a large extent on the principles of evidence-based medicine (EBM). But many complex questions about the most effective ways to influence behaviour and improve health are simply not

H. Rutter $(\bowtie)$

London School of Hygiene and Tropical Medicine,

Keppel Street, London WC1E 7HT, UK

e-mail: harry.rutter@1shtm.ac.uk amenable to this kind of assessment. There is a fundamental epistemological difference between the rigorous EBM methods that can differentiate between two treatments, and the kinds of research that are able to identify effective, sustainable approaches within complex adaptive systems. We need to move from evidence to knowledge (Rayner and Lang 2012), but public health remains largely in thrall to the EBM approach. In obesity, despite the rhetoric of complexity becoming commonplace, there is still a strong intellectual dependence upon systematic reviews and other forms of putatively robust and defensible evidence.

The concept of complexity in health care, and in public health, has been around for some years now (Plsek and Greenhalgh 2001), but remains on the margins of the majority of health and policy activity. This may be at least partly because of the inherent challenge of the perspective to a discipline grounded in biomedicine. Randomised controlled trials and meta analyses are the kinds of tools that have successfully dragged us away from the unhelpful biases of expert opinion and led us to disinterested objectivity. But non-linear systems with feedback, interactions, emergence, compensatory behaviours and small effect sizes are not suited to dichotomous hypothesis testing, resulting in few robust studies and often very little to review. The job of public health is not the same as the one we started on a few years ago, and now is the time for some new tools, and new skills to use them.

These tools are commonly used in other fields, such as climate change modelling, defence, and business. They involve a significant shift in thinking, from linear cause and effect to non-linear system-wide dynamics, and much greater tolerance of uncertainty and unpredictability. These ways of thinking allow us to conceptualise and respond to systems problems such as obesity in far more effective 
ways than traditional approaches, and apply objective scientific analysis and reasoning in place of subjective opinion (OECD 2009; Malhi et al. 2009).

As described elsewhere, there are structural barriers to these developments, with research funding and academic hierarchies tending to promote focus and specialisation rather than breadth (Rutter 2011). But a systems approach involves more than just greater breadth-it requires a move beyond reductionist linear models to engagement with nonlinear complexity. Interdisciplinary research is a step towards this, but may just be the last gasp of an old paradigm, before the disciplinary boundaries are properly dissolved and a true systems approach prevails.

The intellectual key to understanding obesity is to pursue that shift of paradigm, in the true sense of the phrase (Kuhn 1996), from conceptualising it as a complicated system, with many parts that interact in predictable linear ways, to understanding it as a complex one, with all that entails. It is very hard to reject a paradigm, but as the incommensurable gradually becomes irreconcilable, something will have to change. Perhaps, just perhaps, if I'm approached again in a few years time for advice on tackling obesity I will be asked a different kind of question...

Harry Rutter

London, May 2012
Conflict of interest I have no conflicts of interest.

\section{References}

Butland B, Jebb S, Kopelman P et al (2007) Tackling obesities: future choices - project report. Government Office for Science, London

Finegood D, Merth T, Rutter H (2010) Implications of the foresight obesity system map for solutions to childhood obesity. Obesity 18:S13-S15

Kuhn T (1996) The structure of scientific revolutions, 3rd edn. University of Chicago Press, Chicago

Malhi L, Karanfil O, Merth T, Acheson M, Palmer A, Finegood D (2009) Places to intervene to make complex food systems more healthy, green, fair, and affordable. J Hunger Environ Nutr 4(3):466-476. doi:10.1080/19320240903346448

OECD (2009) Global Science Forum. Applications of complexity science for public policy: new tools for finding unanticipated consequences and unrealized opportunities. http://www.oecd. org/dataoecd/44/41/43891980.pdf. Accessed 27 May 2012

Plsek PE, Greenhalgh T (2001) Complexity science: the challenge of complexity in health care. BMJ 323(7313):625-628

Raine K (2012) Obesity epidemics: inevitable outcome of globalization or preventable public health challenge? Int J Public Health 57:35-36

Rayner G, Lang T (2012) Ecological public health: reshaping the conditions of good health. Earthscan, London, ISBN: 9781844078325

Rutter H (2011) Where next for obesity? Lancet 378(9793):746-747. doi:10.1016/S0140-6736(11)61272-5 